University of Nebraska - Lincoln

DigitalCommons@University of Nebraska - Lincoln

Biological Systems Engineering: Papers and

Publications

Biological Systems Engineering

2010

\title{
Cytocompatible cross-linking of electrospun zein fibers for the development of water-stable tissue engineering scaffolds
}

\author{
Quiran Jiang \\ University of Nebraska-Lincoln \\ Narendra Reddy \\ University of Nebraska-Lincoln, nreddy3@unl.edu \\ Yiqi Yang \\ University of Nebraska-Lincoln, yyang2@unl.edu
}

Follow this and additional works at: https://digitalcommons.unl.edu/biosysengfacpub

Part of the Biological Engineering Commons

Jiang, Quiran; Reddy, Narendra; and Yang, Yiqi, "Cytocompatible cross-linking of electrospun zein fibers for the development of water-stable tissue engineering scaffolds" (2010). Biological Systems Engineering: Papers and Publications. 193.

https://digitalcommons.unl.edu/biosysengfacpub/193

This Article is brought to you for free and open access by the Biological Systems Engineering at DigitalCommons@University of Nebraska - Lincoln. It has been accepted for inclusion in Biological Systems Engineering: Papers and Publications by an authorized administrator of DigitalCommons@University of Nebraska Lincoln. 


\title{
Cytocompatible cross-linking of electrospun zein fibers for the development of water-stable tissue engineering scaffolds
}

\author{
Qiuran Jiang, ${ }^{1}$ Narendra Reddy, ${ }^{1}$ and Yiqi Yang ${ }^{1,2,3}$
}

1. Department of Textiles, Clothing and Design, University of Nebraska-Lincoln

2. Department of Biological Systems Engineering, University of Nebraska-Lincoln

3. Nebraska Center for Materials and Nanoscience, University of Nebraska-Lincoln

Corresponding author - Y. Yang, Department of Biological Systems Engineering, 234 HECO Building. University of Nebraska-Lincoln, Lincoln, NE 68583-0802, USA; tel 402 472-5197, fax 402 472-0640, email yyang2@unl.edu

\begin{abstract}
This paper reports a new method of cross-linking electrospun zein fibers using citric acid as a non-toxic cross-linker to enhance the water stability and cytocompatibility of zein fibers for tissue engineering and other medical applications. The electrospun structure has many advantages over other types of structures and protein-based biomaterials possess unique properties preferred for tissue engineering and other medical applications. However, ultrafine fiber matrices developed from proteins have poor mechanical properties and morphological stability in the aqueous environments required for medical applications. Efforts have been made to improve the water stability of electrospun protein scaffolds using cross-linking and other approaches, but the current methods have major limitations, such as cytotoxicity and low efficiency. In this research electrospun zein fibers were cross-linked with citric acid without using any toxic catalysts. The stability of the cross-linked fibers in phosphate-buffered saline and their ability to support the attachment, spreading, and proliferation of mouse fibroblast cells were studied. The cross-linked electrospun fibers retained their ultrafine fibrous structure even after immersion in PBS at $37^{\circ} \mathrm{C}$ for up to 15 days. Citric acid cross-linked electrospun zein scaffolds showed better attachment, spreading, and proliferation of fibroblast cells than uncross-linked electrospun zein fibers, cross-linked zein films, and electrospun polylactide fibers.
\end{abstract}

Keywords: zein, electrospinning, citric acid cross-linking, cytocompatibility, water stability

\section{Introduction}

Currently, extensive efforts are being made to develop protein-based biomaterials for biomedical applications [1, 2]. Having similar macromolecular structures to naturally occurring proteins in tissues and organs, protein-based biomaterials have the potential to provide biological functionality and can be degraded by natural enzymes and metabolized by physiological mechanisms [3]. Moreover, proteins possess inherent complex structures which show tunable charges in different $\mathrm{pH}$ environments and also have hydrophobic sections capable of hydrophobic interactions. Thus, proteins show flexible adsorption to various substrates and, hence, the potential to serve as carriers of proteins, cells, drugs and growth factors [4, 5]. Among the various types of biomaterials being developed, electrospun materials composed of ultra fine fibers are preferred for medical applications. Electrospun structures closely mimic the three-dimensional (3D) fibrous network found in the natural extracellular matrix (ECM) [6-9]. Electrospun materials also have a high surface to volume ratio that facilitates cell attachment and drug sorption $[6,10]$ and contain a large volume of interconnected pores, which assist in the transportation of oxygen, nutrients and the metabolic waste of cells and cell migration and communication [8]. Therefore, protein-based electrospun fibers have been developed in order to combine the advantages of protein materials and electrospun structures for biomedical applications [11-17].

However, the electrospun protein fibers developed so far have poor stability in aqueous environments, which restricts their biomedical applications [16]. When immersed in water electrospun protein fiber mats swell and collapse into films with a considerable decrease in surface area, the number of interconnected pores, and tensile strength [18]. Therefore, efforts have been made to improve the water stability of electrospun protein fibers. One approach is to blend proteins with other natural and synthetic polymers, which are more water stable. For example, collagen was blended with poly(ethylene oxide) (PEO) [19] or polydioxanone (POD) [20] to produce electrospun fibers. The collagen-PEO/PDO fiber blends displayed improved mechanical properties and better shape retention. Although more successful cases could be listed, blending still has several limitations. Under some circumstances it may be challenging to dissolve certain proteins and polymers in one nontoxic solvent that is suitable for electrospinning. Besides, some properties of blended polymers, such as high hydrophobicity or poor degradability, may cause undesirable changes to the 
surface properties and the biodegradability of the final electrospun protein fibers. Therefore, chemical modifications such as cross-linking have been used as alternatives to polymer blending. However, most cross-linking agents used to crosslink electrospun protein fibers are toxic [21-29], expensive [10] and/or inefficient in providing the desired improvement in water stability of the fibers [10,16].

Recently we developed a non-toxic method of cross-linking plant proteins in the wet state using carboxylic acids as crosslinkers and alkali as catalyst. The cross-linking method developed by us provided protein fibers with improved water stability and an up to 5-fold increase in breaking strain [30]. The carboxylic acids (citric acid and malic acid) used in our previous research are cytocompatible, since they are the intermediate products in a metabolic pathway and, therefore, suitable to modify biomaterials. However, the method of carboxylic acid cross-linking developed in our previous research was for the modification of fibers of relatively large diameter and required immersing the fibers in the alkaline cross-linking solution. Since the electrospun fibers were unstable and became film-like when immersed in the cross-linking solution, this wet cross-linking method was unsuitable for the modification of electrospun protein mats. In similar research on cross-linking plant proteins, micro- and nano-scale zein fibers were cross-linked using citric acid as the cross-linking agent and sodium hypophosphite monohydrate (SHP) as the catalyst and cross-linking was carried out in the dry state at high temperature $\left(150-175^{\circ} \mathrm{C}\right)[31,32]$. However, the catalyst SHP was reported to be cytotoxic $[33,34]$ and hence not suitable to cross-link electrospun fibers used for biomedical applications. Although carboxylic acids such as citric acid are biocompatible and can improve the properties of protein fibers, the current approaches to carboxylic acid cross-linking of plant proteins are unsuitable for cross-linking electrospun plant protein fibers for biomedical applications.

Although plant proteins such as zein have been used to develop films and other substrates for tissue engineering and other medical applications, there are no reports on developing electrospun plant protein fibers. In addition, fibrous materials developed from plant proteins need to be cross-linked to make them useful for medical applications. While it has been shown that plant proteins can be cross-linked with non-toxic carboxylic acids, current methods of carboxylic acid cross-linking are not suitable for cross-linking electrospun plant protein fibers. To the best of our knowledge there are no methods of developing electrospun plant protein fibers with the cytocompatibility, mechanical properties, and water stability required for tissue engineering and other medical applications.

The purpose of this research was to develop a non-toxic cross-linking method that can provide electrospun protein fibers with the water stability required for biomedical applications. Zein was chosen for the study among other proteins since zein has been reported to be biodegradable and biocompatible. As a plant protein, zein has a much lower possibility of transmitting zoonotic diseases, which may occur with some animal proteins, such as collagen [35]. Moreover, since zein can be dissolved in aqueous ethanol solutions, it is relatively easy and environmentally friendly to produce electrospun fibers from zein. In addition, zein shares the common problems of other protein-based biomaterials, such as a low tensile strength and poor morphological stability in an aqueous environment, especially when made into electrospun fibers. Therefore, in this study zein was employed as a protein model to produce electrospun fibers, which were cross-linked with citric acid for potential biomedical applications. The improvements in tensile strength and water stability were evaluated. The attachment, spreading and growth of NIH 3T3 mouse fibroblast cells on the cross-linked electrospun zein fibers were investigated and compared with those on polylactic acid (PLA) electrospun fibers and films, uncross-linked electrospun zein fibers, citric acid cross-linked electrospun zein mats catalyzed by SHP, as well as citric acid cross-linked zein films.

\section{Materials and methods}

\subsection{Preparation of scaffolds}

Table 1 summarizes the conditions for the samples prepared in this research. The cross-linked electrospun zein samples (XL-L, XL-M, and XL-H) were produced based on the conditions chosen from our preliminary researches on crosslinking electrospun zein mats and coarse fibers from other plant proteins (data not shown). The cross-linking solution containing 5.5, 7, or 9 wt. \% citric acid (on weight of zein) were prepared by dissolving citric acid (EMD Chemicals, Inc.) in 70 wt. \% ethanol (EMD Chemicals, Inc.). The cross-linking solutions obtained after dissolution of citric acid had $\mathrm{pH}$ values around 2. However, our previous research showed that the effect of citric acid cross-linking was enhanced by increasing the $\mathrm{pH}$ of the citric acid solutions [34]. Therefore, the $\mathrm{pH}$ of the cross-linking solution was adjusted to 4.9 by adding sodium hydroxide solution (in $70 \%$ ethanol, $0.125 \mathrm{~g} \mathrm{ml}^{-1}$ ). Although a $\mathrm{pH}$ higher than 4.9 was preferable for cross-linking, it was not possible to obtain a cross-linking solution with a higher $\mathrm{pH}$ because phase separation occurred when more sodium hydroxide solution was added.

Zein solutions (50 wt.\%) were prepared by dissolving zein powders (F-4000, Freeman Industries LLC) in the $\mathrm{pH}$-adjusted citric acid solution. Pre-cross-linking was performed by ageing the zein solutions in sealed containers for $48 \mathrm{~h}$ at room temperature, in order to allow expansion of zein molecular chains and formation of cross-links. After pre-cross-linking the concentrations of pre-cross-linked zein stock solutions were diluted from 50 to $26 \mathrm{wt}$ \% with $70 \mathrm{wt}$. \% ethanol in order to obtain the zein solutions for electrospinning. The electrospinning was carried out at an extrusion rate of $2 \mathrm{ml} \mathrm{h}^{-1}$ with an applied voltage of $19.5 \mathrm{kV}$. The distance between the tip of the extruding syringe needle and the aluminum foil wrapped on the winding drum was maintained at $20 \mathrm{~cm}$. The collecting drum was rotated at $1200 \mathrm{rpm}$. After spinning, the electrospun zein mats were post-cross-linked by heating the electrospun mats at $150{ }^{\circ} \mathrm{C}$ for $2.5 \mathrm{~h}$ in an oven (Mechanical Oven, Lindberg/Blue M, Asheville, NC). Uncross-linked electrospun zein mats were also prepared to serve as controls. The control samples were prepared using the same procedure except adding citric acid.

Electrospun zein fibers were also prepared using our previous method of cross-linking zein using citric acid in the presence of SHP as catalyst in order to evaluate the effect of SHP on cells [32]. The zein solution was aged for $48 \mathrm{~h}$ at $50 \mathrm{wt}$. $\%$ with $6.0 \mathrm{wt}$ \% (on weight of zein) citric acid and $3.3 \mathrm{wt}$ \% (on weight of zein) SHP (Sigma-Aldrich, Inc.). After being diluted to 26 wt.\% with 70 wt.\% ethanol, the zein solution was electrospun under the same conditions to produce samples XL-L, XL-M, and XL-H. The fibers obtained were cross-linked at $150{ }^{\circ} \mathrm{C}$ for $30 \mathrm{~min}$ (the optimized conditions in our previous research [32]).

For comparison with electrospun fibers, uncross-linked and cross-linked zein films were also prepared. Initially, $50 \mathrm{wt}$ \% zein solutions with and without $7 \mathrm{wt}$ \% (weight of zein) citric acid were prepared and aged for $48 \mathrm{~h}$. The solutions were later diluted with $70 \mathrm{wt} . \%$ ethanol to $7 \mathrm{wt} . \%$ and cast onto flat bottomed glass plates and dried overnight under ambient conditions. The zein films obtained were further heated at $150{ }^{\circ} \mathrm{C}$ for $2.5 \mathrm{~h}$ for the cross-linking reaction to occur.

Films and electrospun fibers were also made from PLA (Cargill Dow LLC) to compare the performance of PLA with 
Table 1. Samples and their preparation conditions.

\begin{tabular}{lllll}
\hline Index & Sample & $\begin{array}{l}\text { Pre-cross-linking and } \\
\text { ageing conditions }\end{array}$ & $\begin{array}{l}\text { Spinning/casting } \\
\text { concentration (\%) }\end{array}$ & $\begin{array}{l}\text { Post-cross-linking } \\
\text { conditions }\end{array}$ \\
\hline PLAF & PLA film & $7 \%, 24 \mathrm{~h}$ & 7 & 7 \\
PLA & PLA electrospun fiber mat & $7 \%, 24 \mathrm{~h}$ & 7 & 7 \\
ZFUL & Zein uncross-linked film & $50 \%$ zein, $48 \mathrm{~h}$ & 26 & $150^{\circ} \mathrm{C}, 2.5 \mathrm{~h}$ \\
ZFXL & Zein cross-linked film & $50 \%$ zein, $7 \% \mathrm{CA}, 48 \mathrm{~h}$ & $150^{\circ} \mathrm{C}, 2.5 \mathrm{~h}$ \\
UXL & Zein uncross-linked electrospun fiber mat & $50 \%$ zein, $48 \mathrm{~h}$ & $150^{\circ} \mathrm{C}, 2.5 \mathrm{~h}$ \\
SHPXL & Zein cross-linked electrospun fiber mat & $50 \%$ zein, $6 \% \mathrm{CA}, 3.3 \% \mathrm{SHP}, 48 \mathrm{~h}$ & 26 & $150^{\circ} \mathrm{C}, 30 \mathrm{~min}$ \\
XL-L & Zein cross-linked electrospun fiber mat & $50 \%$ zein, $5.5 \% \mathrm{CA}, 48 \mathrm{~h}$ & 26 & $150^{\circ} \mathrm{C}, 2.5 \mathrm{~h}$ \\
XL-M & Zein cross-linked electrospun fiber mat & $50 \%$ zein, $7 \% \mathrm{CA}, 48 \mathrm{~h}$ & 26 & $150^{\circ} \mathrm{C}, 2.5 \mathrm{~h}$ \\
XL-H & Zein cross-linked electrospun fiber mat & $50 \%$ zein, $9 \% \mathrm{CA}, 48 \mathrm{~h}$ & 26 & $150^{\circ} \mathrm{C}, 2.5 \mathrm{~h}$ \\
\hline
\end{tabular}

CA, citric acid.

a. Based on the optimum conditions from our previous study.

zein films and electrospun fibers, PLA powder was dissolved in chloroform at $7 \mathrm{wt} \%$ and the solutions were sealed and aged for $24 \mathrm{~h}$ for complete dissolution, PLA films were obtained by casting the solution on glass plates followed by drying overnight under ambient conditions. Electrospun PLA fiber mats were produced by extruding the aged 7 wt.\% PLA solution in chloroform at a rate of $1 \mathrm{ml} \mathrm{h}^{-1}$ with an applied voltage of $18 \mathrm{kV}$. The distance between the tip of the needle and surface of the winding drum was kept at $15 \mathrm{~cm}$ and the rate of rotation of the drum was $1200 \mathrm{rpm}$.

\subsection{Tensile tests}

The effects of cross-linking on the tensile strength of the cross-linked and uncross-linked electrospun zein fibers were investigated. Fiber mats for tensile tests, $2 \mathrm{~cm}$ in length and $1.5 \mathrm{~cm}$ in width, were prepared on pieces of aluminum foil that supported the fibers during testing. The aluminum foils used for testing were cut in the middle parallel to the long sides before electrospinning in order to ensure that the tensile strength was measured only on the fibers rather than the foils. Before testing, all the samples were conditioned at $21^{\circ} \mathrm{C}$ and $65 \%$ relative humidity for $24 \mathrm{~h}$. The tensile strength was measured in terms of the maximum load in an Instron 4444 universal testing machine (Canton, MA) with a gauge length of $9 \mathrm{~mm}$ and a crosshead speed of $18 \mathrm{~mm} \mathrm{~min}{ }^{-1}$. At least 15 specimens were tested for each type of sample. After testing, the tensile strengths of the mats were calculated using the following equation:

$$
\sigma_{\max }=F / S_{1}
$$

where $\sigma_{\max }$ is the tensile strength of the electrospun fiber mat, $F$ is the maximum load and $S_{1}$ is the sum of the cross-sectional area of all the fibers on each piece of mat, which was calculated according to the equation:

$$
S_{1}=M /\left(\rho \times L_{1}\right)
$$

where $M$ is the mass of the fibers on each piece of foil, $L_{1}$ is the length of each foil $(2 \mathrm{~cm})$ and $\rho$ is the material density of each sample. To determine the material density of each sample fibers were prepared on 12 coverslips instead of aluminum foils in order to facilitate observation under a light microscope (Olympus CH30). The material density of each sample was calculated by the equation:

$$
\rho=m /\left[S_{2} \times L_{2} \times\left(S_{3} / S_{4}\right)\right]
$$

where $m$ is the mass of the fibers on the 12 coverslips, $S_{2}$ is the average cross-sectional area of a single fiber, $L_{2}$ is the total length of fibers in the microscope image, $S_{3}$ is the total area of the 12 coverslips and $S_{4}$ is the area of the image seen under the microscope. The cross-sectional area of single fibers was calculated from the average single fiber diameter, which was measured from scanning electron microscopy (SEM) images (S3000N, Hitachi) at 3500× magnification. The total fiber length on the 12 coverslips was calculated from the fiber length in each image ( 3 images per sample), the area of each image taken by the microscope, and the total area of the 12 coverslips.

\subsection{Water stability tests}

The water stability of the cross-linked and uncross-linked electrospun zein mats were studied in phosphate-buffered saline $(1 \times$ PBS, pH 7.4). Samples $(2 \mathrm{~cm}$ in length, $1.5 \mathrm{~cm}$ in width) were sterilized under UV light overnight, incubated in PBS for 2 or 15 days at $37^{\circ} \mathrm{C}$ and then washed with distilled water twice, followed by drying overnight under ambient conditions. The morphological changes in the samples were observed by SEM at $1500 \times$ and $4000 \times$ magnification (three specimens for each sample). The fiber diameters were measured on at least 10 samples to evaluate swelling of the fibers in the mats.

\subsection{Zeta potentials of scaffold materials}

The $\zeta$ potentials of the zein fibers cross-linked with 5.5, 7.0, and $9.0 \mathrm{wt}$ \% citric acid and PLA were measured to investigate the effect of surface charge on cell attachment. To prepare the dispersions of zein samples, $35 \mathrm{mg}$ of electrospun fiber mats were dissolved in $1.5 \mathrm{ml}$ of $70 \%$ ethanol, followed by mixing $0.5 \mathrm{ml}$ of zein solution in $5 \mathrm{ml}$ of culture medium (Dulbecco's modified low-glucose Eagle's medium [Sigma-Aldrich] containing $10 \%$ calf serum [Colorado Serum Company], 1.4 vol. $\%$ $200 \mathrm{mM}$ L-glutamine [Sigma-Aldrich] and $0.1 \mathrm{mg} \mathrm{ml}^{-1}$ penicillin/streptomycin [ATCC]). The dispersion of PLA samples were prepared by dissolving $35 \mathrm{mg}$ of PLA powder in $1.5 \mathrm{ml}$ of chloroform and later mixing $0.5 \mathrm{ml}$ of PLA chloroform solution in $1 \mathrm{ml}$ of ethanol and adding $1.5 \mathrm{ml}$ of the mixture to 5 $\mathrm{ml}$ of culture medium. The dispersions of zein and PLA samples were placed in a vacuum chamber to evaporate the ethanol and chloroform at room temperature. Five specimens were prepared for each sample. The $\zeta$ potentials were measured in a particle size analyzer (Model Delsa Nano C, Beckman Coulter, Brea, CA) according to the instructions provided by the manufacturer.

\subsection{Cytocompatibility evaluation}

In this research NIH $3 \mathrm{~T} 3$ mouse fibroblast cells were used to evaluate the cytocompatibility of the scaffolds. Cells were cultured in culture medium at $37{ }^{\circ} \mathrm{C}$ in a humidified $5 \% \mathrm{CO}_{2}$ atmosphere and were passaged every 3 days.

Methanethiosulfonate (MTS) assays were conducted to quantitatively investigate cell attachment and proliferation. Four specimens were prepared for each sample with a diameter of $10 \mathrm{~mm}$, washed in distilled water three times and dried at room temperature. Zein films and electrospun mats were subjected to sterilization at $120^{\circ} \mathrm{C}$ for $1 \mathrm{~h}$ and PLA scaffolds were sterilized in $75 \%$ aqueous ethanol for $1 \mathrm{~h}$. Different ster- 
ilization methods were applied to the zein and PLA scaffolds because PLA could not withstand high temperatures while zein scaffolds dissolved in $75 \%$ ethanol. To obtain sufficient sterilization both the zein and PLA scaffolds were subjected to one more step of UV sterilization for around $8 \mathrm{~h}$. Longer sterilization under UV was not applied to avoid possible degradation of the polymers. After sterilization the scaffolds were placed in 48-well culture plates. Fibroblast cells were seeded onto the scaffolds $\left(1 \times 10^{5}\right.$ cells ml $\left.^{-1}, 500 \mu \mathrm{lwell}^{-1}\right)$ and then cultured at $37{ }^{\circ} \mathrm{C}$ in a humidified $5 \% \mathrm{CO}_{2}$ atmosphere for 8 and $24 \mathrm{~h}$. At each time point the samples were washed with PBS, placed in new 48-well plates containing $450 \mu \mathrm{l} \mathrm{well}^{-1} 20 \%$ MTS reagent (CellTiter $96{ }^{\circledR}$ Aqueous One Solution Cell Proliferation Assay, Promega) in Dulbecco's modified Eagle's medium (DMEM) and incubated at $37^{\circ} \mathrm{C}$ in a humidified $5 \% \mathrm{CO}_{2}$ atmosphere for $3 \mathrm{~h}$. After incubation, $150 \mu \mathrm{l}$ of the solution from each well was pipetted into a 96-well plate and the optical densities were measured at $490 \mathrm{~nm}$ using a UV/Vis multiplate spectrophotometer (Multiskan ${ }^{\circledR}$ Spectrum, Thermo Scientific). The MTS solution in DMEM without cells served as the blank. The cell numbers were calculated based on a calibration curve.

Cells were cultured for 8-120 h on the samples SHPXL and $\mathrm{XL}-\mathrm{H}$ to study the influence of the catalyst SHP on cell growth. Although the cell numbers after a particular time point would indicate the performance of each type of scaffold in terms of supporting cell growth, it was not reasonable to evaluate the toxicity of SHP to cells based on the final cell numbers, since the numbers of cells initially attached to the scaffolds were different. Therefore, we used normalized cell growth values to investigate the proliferation rates based on the following equation:

$$
K(\%)=\left[\left(B_{i+1}-B_{i}\right) / B_{i}\right] \times 100 .
$$

where $K$ is the normalized cell growth kinetic value $(\%), B_{i}$ is the optical density value at time point $i$ and $B_{i+1}$ is the optical density value at a later time point $i+1$.

Genomic DNA quantification assay was used to confirm the results of the MTS assay. Three specimens $(10 \mathrm{~mm}$ in diameter) for each sample were prepared, washed and sterilized according to the methods used in the MTS assay. In order to collect sufficient amounts of DNA for tests, a higher number of cells $\left(7 \times 10^{5}\right.$ cells ml-1, $1 \mathrm{ml}^{-1}$ well $\left.^{-1}\right)$ were seeded compared with the number used in the MTS assay. All the samples were cultured in 48 -well plates at $37^{\circ} \mathrm{C}$ in a humidified $5 \% \mathrm{CO}_{2}$ atmosphere. After $24 \mathrm{~h}$ the number of cells on the samples were determined by the fluorometric quantification of DNA. Cells on each sample were detached by trypsinization and collected after centrifugation. The DNA in the cells was extracted using a QIAamp DNA Mini Kit (Qiagen) according to the manufacturer's protocol. The fluorescence intensity of a mixture of DNA solution $(0.4 \mathrm{~g})$ and $10 \mu \mathrm{g} \mathrm{ml}^{-1}$ Hoechst 33258 fluorescent dye solution (Sigma-Aldrich) (0.4 g) was measured with a fluorescent plate reader (Fluoroskan Ascent FL Series, Labsystems) at $390 \mathrm{~nm}$ for excitation and $460 \mathrm{~nm}$ for emission. The numbers of cells on the scaffolds were calculated based on the calibration curve, which had a linear relationship between fluorescence intensity and the number of cells. The calibration curve was constructed from the fluorescence intensities of cell solutions with a series of cell densities $\left(5.9 \times 10^{5}, 5.0 \times 10^{5}, 3.5\right.$ $\times 10^{5}, 1.8 \times 10^{5}$, and $1.0 \times 10^{5}$ cells $\mathrm{ml}^{-1}$ ).

\subsection{Cell spreading and cytoskeletal observation}

In order to study the spreading of cells and development of the cytoskeleton, immunofluorescent observations were carried out. Samples (3 specimens for each sample, $10 \mathrm{~mm}$ in diameter) were washed and sterilized according to the methods used in the MTS assay. Compared with the cell densities used in the MTS and DNA assays, a relatively low density of cells $\left(5 \times 10^{3}\right.$ cells $\left.\mathrm{ml}^{-1}\right)$ was used for cell seeding, in order to avoid confluence of the cells and to facilitate investigation of the development of the cytoskeleton in individual cells. After $24 \mathrm{~h}$ culture samples were washed with PBS, fixed with $4 \%$ paraformaldehyde (Electron Microscopy Sciences) and permeabilized with $0.1 \%$ Triton X-100 solution (Invitrogen) for $5 \mathrm{~min}$. After another wash with PBS the samples were incubated in Phalloidin 633 solution (1:200 Alexa Fluor ${ }^{\circledR} 633$ Phalloidin, Invitrogen) with $0.1 \%$ Tween 205 (0\% solution, Invitrogen) for 2.5 h. Alexa Fluor ${ }^{\circledR} 633$ Phalloidin is a far red fluorescent dye that specifically bonds to F-actin in cells. This dye was chosen because zein shows fluorescence across the full spectrum, with the weakest signal in the far red range. Cell spreading and the generation of cytoskeletal F-actin were observed under a confocal laser scanning microscope (Olympus FV500) at 100× and $600 \times$ magnification. The fluorescence emission of zein fibers was collected through separate detector channels at a wavelength of $488 \mathrm{~nm}$, while the fluorescence emission of F-actin was investigated at a wavelength of $633 \mathrm{~nm}$.

\subsection{Statistical analysis}

A one-way analysis of variance with Tukey's pairwise multiple comparison was employed to analyze the data. The confidence interval was set at $95 \%$ and a $P$ value less than 0.05 was considered to be a statistically significant difference. In the following results data labeled with the same symbols or characters were not significantly different from each other. The error bars shown in the figures indicate the standard deviations of the data.

\section{Results and discussion}

\subsection{Tensile strength}

The results of uniaxial tensile testing on the cross-linked and uncross-linked zein samples are provided in Table 2. Compared with uncross-linked fibers, all the cross-linked samples showed statistically significant increases in tensile strength $(P<0.05)$. The increase in the tensile strengths of the cross-linked samples should be due to the formation of amido linkages between the carboxyl groups of citric acid and the amino groups on the peptide chains of zein [30,34]. Crosslinking connected the molecules and also reduced slippage of the molecules during tensile testing. Thus, cross-linking contributed to the increase in the tensile strength of the samples.

Table 2 shows that citric acid concentration could also play an important role in determining the tensile properties of samples. Cross-linking with $9 \%$ citric acid gave the highest tensile strength for sample XL-H, compared with the samples cross-linked with 5.5\% (XL-L) or 7\% (XL-M) citric acid. Increasing the citric acid concentration increased the number of molecules available for cross-linking and enhanced the tensile strength. However, citric acid concentrations higher than 9\% were not used since excessive citric acid could cause overcross-linking and reduce the mechanical properties, as observed in the research of $\mathrm{Xu}$ et al. [32J.

Samples cross-linked with the catalyst SHP (SHPXL) also displayed a statistically significant increase in tensile strength compared with the uncross-linked samples, but lower than the strengths of samples cross-linked with 7\% (XL-M) and 9\% citric acid (XL-H) without SHP. The higher strengths of XL-M and $\mathrm{XL}-\mathrm{H}$ should be due to the higher concentrations of citric acid used during cross-linking (6\% for SHPXL), and thus more cross-links could be formed.

\subsection{Water stability}

The morphological changes and the diameters of the electrospun zein fibers before and after treatment with PBS at $37^{\circ} \mathrm{C}$ 

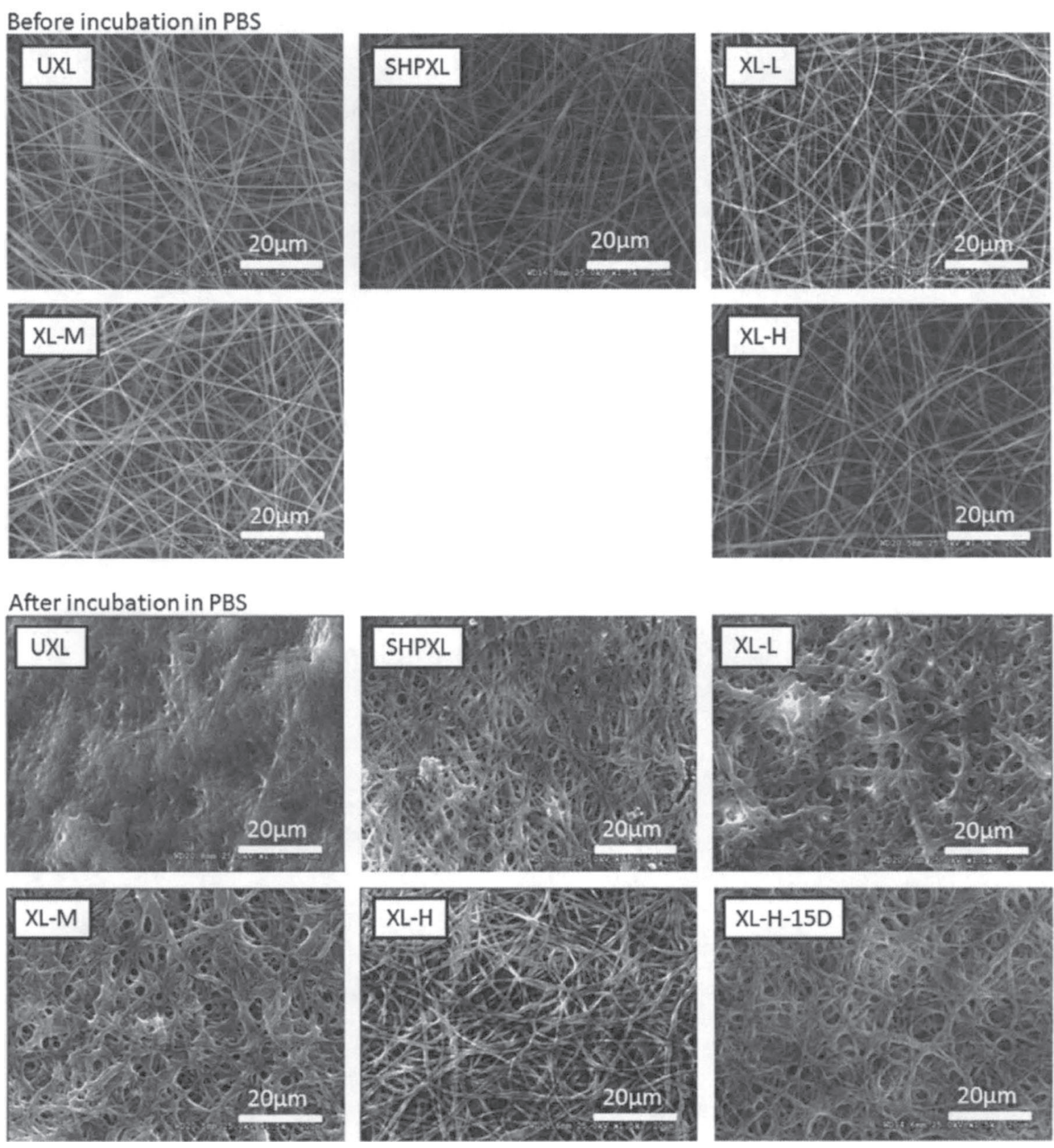

Figure 1. Morphological stability of electrospun zein scaffolds in PBS. The SEM images taken at 1500× magnification display the morphology of the electrospun zein scaffolds before and after incubation in PBS at $37^{\circ} \mathrm{C}$ for 2 or 15 days. The sample abbreviations are given in Table 1 .

Table 2. Tensile strengths of uncross-linked and cross-linked electrospun zein scaffolds.

\begin{tabular}{llllll}
\hline & Index & & & & \\
\cline { 2 - 5 } & UXL & SHPXL & XL-L & XL-M & XL-H \\
\hline $\begin{array}{l}\text { Stress } \\
\text { (MPa) }\end{array}$ & $2.05 \pm 032$ & $2.81 \pm 0.17$ & $3.07 \pm 0.53$ & $3.82 \pm 034$ & $4.02 \pm 0.37$ \\
\hline
\end{tabular}

are shown in Figures 1 and 2. Before incubation all the samples were of similar diameters (around 400-500 nm). After immersion in PBS for $48 \mathrm{~h}$ at $37^{\circ} \mathrm{C}$ the uncross-linked electrospun fiber mats (UXL) could not maintain their fibrous structure and became films. In contrast, all the cross-linked electrospun fiber mats retained their fibrous shape, although the diameters of the cross-linked fibers increased to 2-3.5 times that of uncrosslinked fibers. The amido linkages formed during cross-linking should be mainly responsible for the better water stability of the cross-linked samples. Cross-linking reduced the movement of molecules and prevented swelling of the fibers. Among the cross-linked samples, those cross-linked with the catalyst SHP (SHPXL) displayed an increase in fiber diameter of $125 \%$, lower than that seen in samples XL-L (260\%) and XL-M (175\%), but higher than the swelling in sample XL-H (105\%). The influence of citric acid concentration on fiber water stability can be observed in Figures 1 and 2 (XL-L, XL-M, and XL-H). With increasing citric acid concentration swelling of the cross-linked electrospun zein mats decreased from $260 \%$ to $105 \%$, due to the formation of more cross-links. Since sample XL-H possessed the best water stability, fibers from sample XL-H were treated in PBS at $37^{\circ} \mathrm{C}$ for 15 days. It was found that sample XL-H was capable of maintaining its fibrous structure for 15 days (XL-H$15 \mathrm{D})$ with an increase in diameter of $131 \%$. 


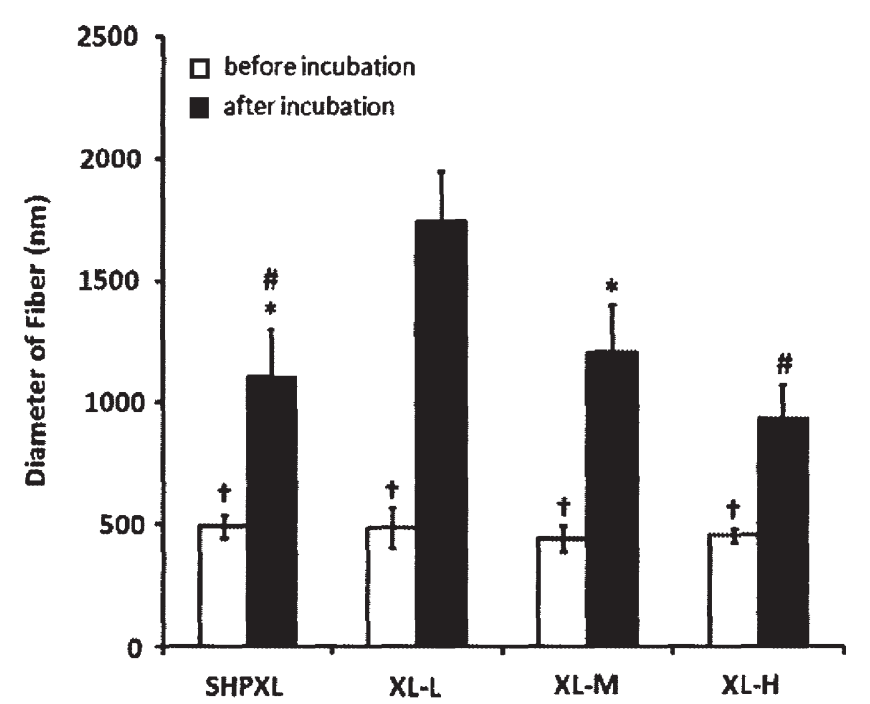

Figure 2. Swelling of electrospun zein fibers. The diameters of crosslinked electrospun zein fibers were measured before and after incubation in PBS at $37^{\circ} \mathrm{C}$ for 2 days. The sample abbreviations are given in Table 1.

\subsection{Effect of cross-linking on cell attachment}

The effects of cross-linking on the attachment of NIH 3 T3 fibroblast cells to scaffolds after $8 \mathrm{~h}$ culture are shown in Figure 3. Cell attachment increased 2-fold on cross-linked zein films (Figure 3, ZFUL vs. ZFXL) and up to 7-fold on cross-linked electrospun fiber mats (Figure 3, UXL vs. XL-H). With increasing citric acid concentration from $5.5 \%$ to $9 \%$, an improvement in fibroblast cell attachment on cross-linked electrospun zein fibers was observed. An increase in the stiffness of the cross-linked zein films and fibers could be one of the major reasons for the higher cell attachment. It has been reported that increasing scaffold stiffness promotes cell attachment and growth [36]. In addition, the cross-linked electrospun zein fibers had improved water stability and retained their high surface to volume ratio and the large volume of interconnected pores, which facilitated cell attachment $[6,10]$.
Figure 3 also shows that cell attachment to electrospun scaffolds cross-linked with SHP (SHPXL) was lower than that to the fibers cross-linked without SHP (XL-L, XL-M, and XL$\mathrm{H})$. As shown in Figure 1, sample XL-H possessed better water stability, which could lead to better cell growth than sample SHPXL. However, cell attachment on samples XL-L and XLM, which showed either similar or poor water stability, were also better than that on sample SHPXL. This suggests that the catalyst SHP might inhibit cell attachment. Compared with citric acid, the SHP molecule is larger and has a stronger affinity for proteins, and, hence, it might be more difficult to remove SHP from the fibers during washing. Any residual SHP in the fibers would contribute negative charges to the fibers, repulse cells, and lower cell attachment.

\subsection{Effect of scaffold structure on cell attachment}

The effects of scaffold structure (films vs. electrospun fibers) on cell attachment can be observed in Figure 3. Cell attachment on electrospun PLA fibers was 1.8-fold of that on PLA films, while cell attachment on the cross-linked electrospun zein fibers was up to 3-fold that on cross-linked zein films. The high surface to volume ratio and large number of pores in the electrospun structures could enhance the adhesion of cells and proteins in the culture medium $[6,10]$. A preference for cell attachment to electrospun fibers over films was also observed by Xua et al. [37]. They reported that aligned nanofibrous electrospun scaffolds of poly(L-lactate-co- $\varepsilon$ caprolactone) (P(LLA-CL)) displayed improved smooth muscle cell attachment and proliferation compared with P(LLACL) films.

\subsection{Effect of the scaffold materials on cell attachment}

Figure 3 also shows that the cross-linked electrospun zein fibers could provide cell attachment up to 2.1-fold higher than that on electrospun PLA fibers. The mean value of cell attachment on zein films was also higher than that on PLA films, although the difference was not statistically significant. It was possible that the charges carried by cross-linked zein and PLA scaffolds playa crucial role in cell attachment. As shown in Table 3 , the $\zeta$ potentials of cross-linked zein in the culture medium

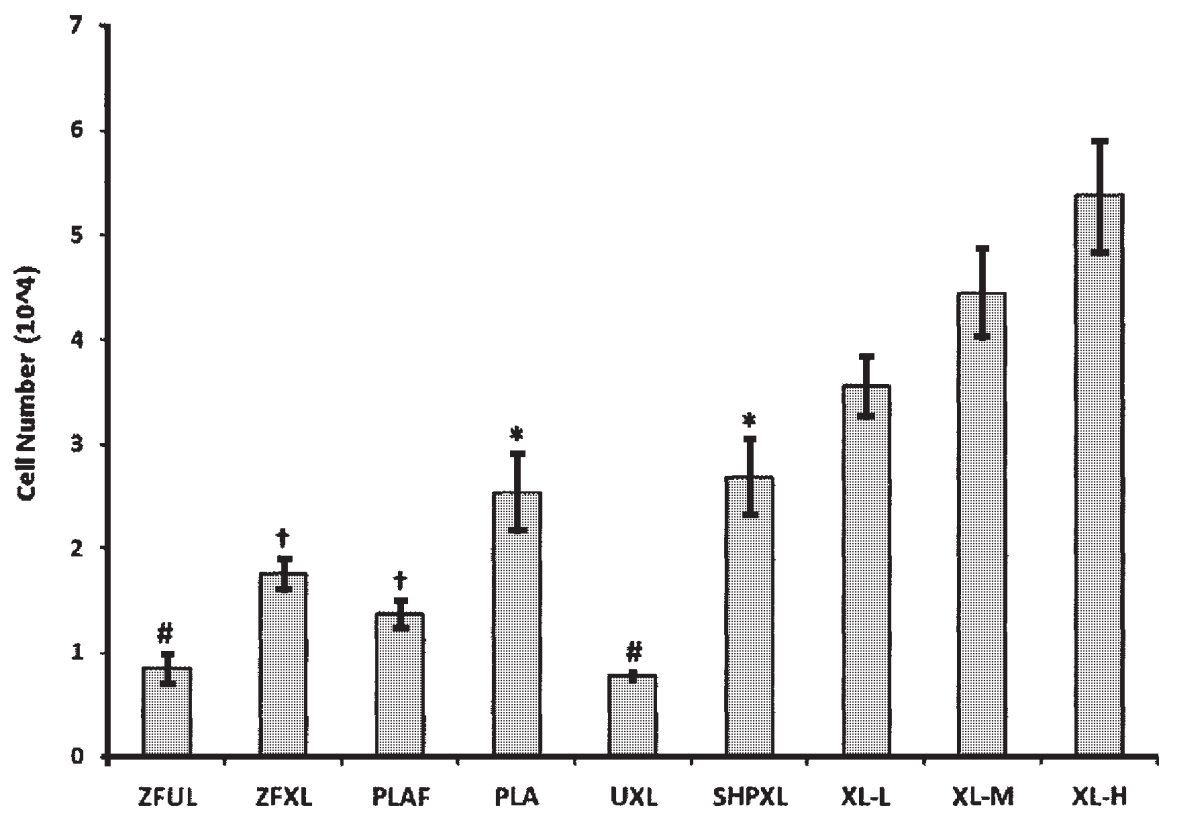

Figure 3. Influence of different scaffolds on cell attachment. The attachment of NIH 3T3 fibroblast cells on zein and PLA electrospun fibers and films after $8 \mathrm{~h}$ culture was evaluated by MTS assay. The sample abbreviations are given in Table 1. 


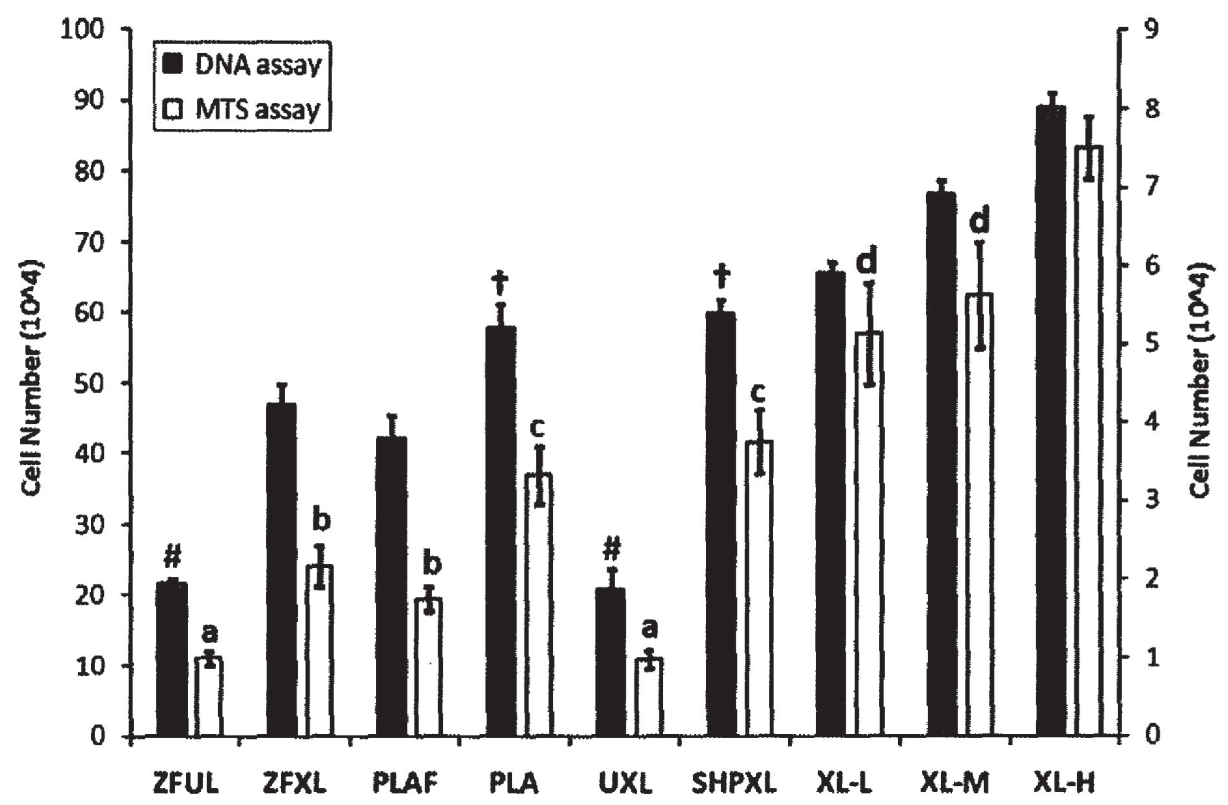

Figure 4. Influence of different scaffolds on cell number after $24 \mathrm{~h}$ growth. The growth of NIH 3 T3 fibroblast cells on zein and PLA electrospun fibers and films after $24 \mathrm{~h}$ culture was evaluated by DNA assay and MTS assay. The sample abbreviations are given in Table 1.

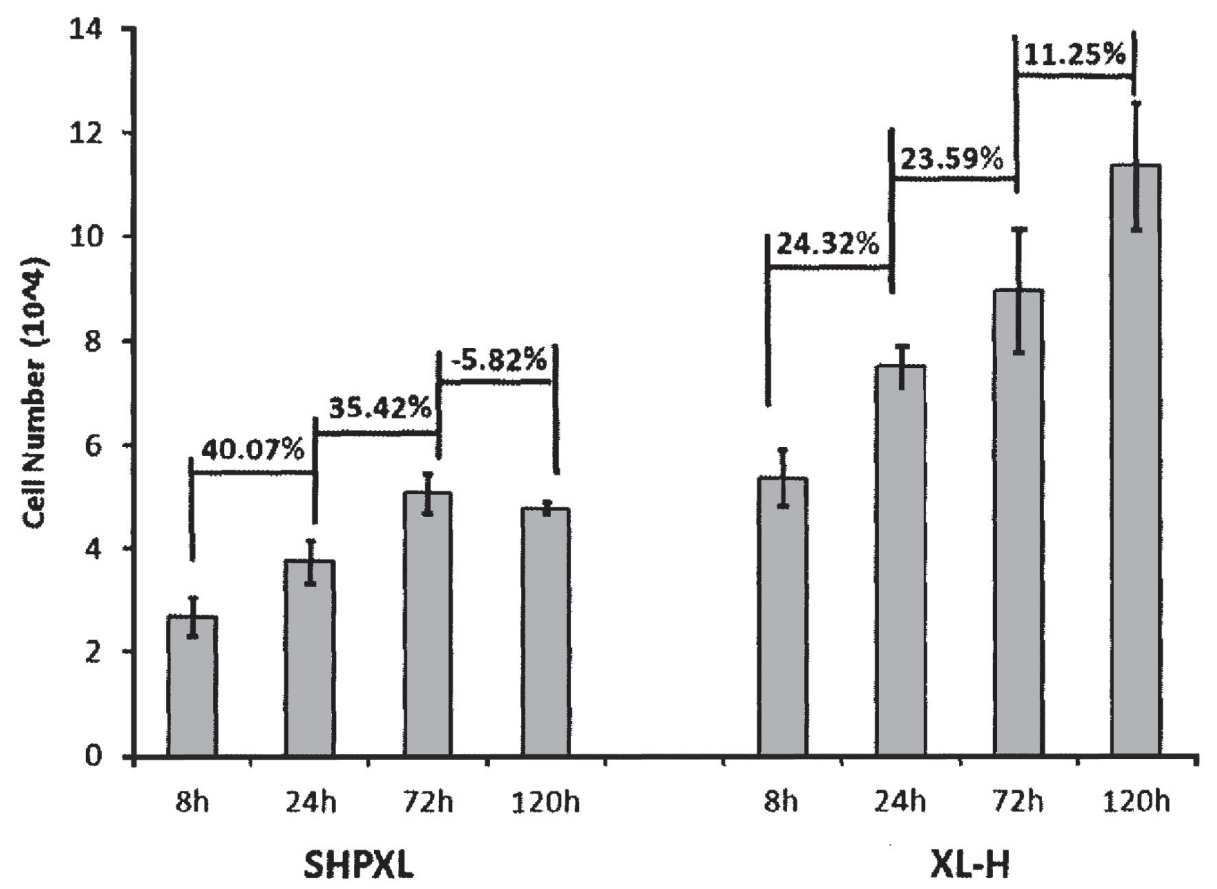

Figure 5. Cytotoxicity of the catalyst SHP. The MTS assay was used to evaluate cell growth on electrospun zein fibers cross-linked by citric acid with (SHPXL) and without (XL-H) catalysis by SHP for up to $120 \mathrm{~h}$ expressed as cell number and normalized cell growth kinetic values. The sample abbreviations are given in Table 1.

Table 3. $\zeta$ potential of PLA and uncross-linked and cross-linked zein.

\begin{tabular}{|c|c|c|c|c|c|}
\hline & \multicolumn{5}{|l|}{ Index } \\
\hline & UXL & SHPXL & XL-L & XL-M & XL-H \\
\hline$\zeta$ potential $(\mathrm{mV})$ & $-65 \pm 13$ & $-93 \pm 1.7$ & $-11.2 \pm 1.5$ & $-10.5 \pm 2.2$ & $-20.1 \pm 1.5$ \\
\hline
\end{tabular}

at $\mathrm{pH} 7.2$ were in the range -9.3 to $-11.2 \mathrm{mV}$. while the $\zeta$ potential of PLA was $-20.1 \mathrm{mV}$. The $\zeta$ potential values suggest that more negative charges were carried by PLA in the cell culture medium than those carried by zein. Since the surfaces of cells carry mostly negative charges, there was a stronger repulsive force between cells and PLA scaffolds than between cells and zein, and hence a lower cell attachment on the PLA scaffolds.

\subsection{Cell growth}

The cell numbers on the scaffolds after $24 \mathrm{~h}$ culture are shown in Figure 4, which displays a similar trend to that of cell attachment. MTS and genomic DNA quantification assays were used to evaluate cell number, since both methods have their limitations. The results of the MTS assay were not only 

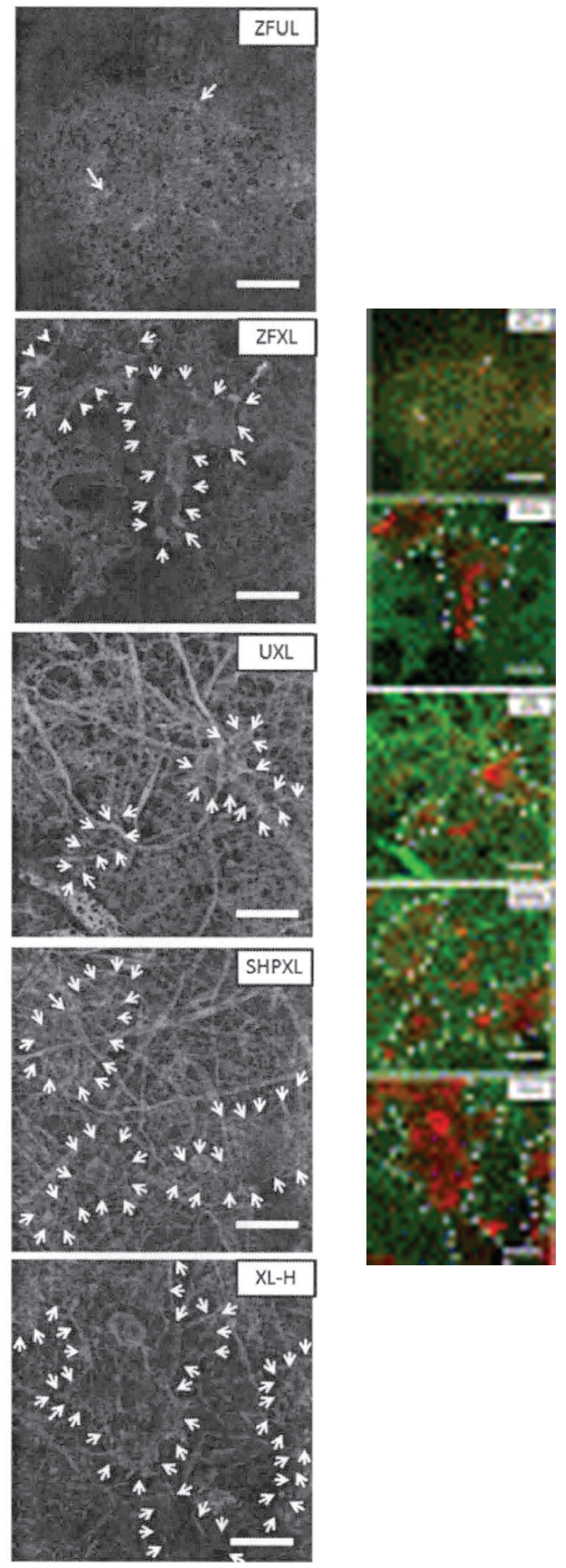

Figure 6. Cell spreading and development of the cytoskeleton. NIH 3T3 fibroblast cells after $24 \mathrm{~h}$ culture were evaluated by immunofluorescent staining. The green areas in the image are zein scaffolds, while the red areas are F-actin in cells stained with Phalloidin 633. Image ZFUL was taken at a magnification of $100 \times$ (scale bar $100 \mu \mathrm{m})$. All the other images were taken at a magnification or $600 \times$ (scale bar $20 \mu \mathrm{m}$ ). The sample abbreviations are given in Table 1 . influenced by cell number but also by the metabolic activity of the cells, whereas the genomic DNA quantification assay counts not only the DNA in living cells but also that in dead cells adhering to the scaffolds after washing.

The results of the MTS and genomic DNA quantification assays showed that the final numbers of cells on the crosslinked zein fibers (SHPXL, XL-L, XL-M, and XL- H) and zein films (ZFXL) after $24 \mathrm{~h}$ were higher than the cell numbers on uncross-linked zein fibers (UXL) and films (ZFUL), due to the enhanced stiffness of the scaffolds [36], and that they retained interconnected pores $[6,10)$.

In addition, cross-linked zein scaffolds performed better than corresponding PLA scaffolds in terms of supporting cell growth (Figure 4, ZFXL vs. PLAF, SHPXL, XL-L, XL-M, and XL-H vs. PLA). Similar results were observed by Dong et al. [38], who demonstrated that films composed of zein particles could serve as a better matrix than PLA for cell growth. However, the reasons for the differences in cell growth between the cross-linked zein scaffolds and PLA scaffolds are not apparent. One plausible reason is that the degradation product of PLA was lactic acid, which would lower the $\mathrm{pH}$ near the PLA scaffolds and lead to reduced cell growth. However, the amino acids released during zein degradation would not influence the $\mathrm{pH}$ near the scaffolds as much as lactic acid and could be absorbed by the cells as nutrients.

Moreover, cell growth on electrospun scaffolds was better than that on the film scaffolds (Figure 4, PLA vs. PLAF, SHPXL, XL-L, XL-M, and XL-H vs. ZFXL), since the porous structure of electrospun fiber mats was able to facilitate the transportation of oxygen, nutrients, and the metabolic waste of cells, and the migration of cells and communication between them, all of which contribute to better cell growth [15, 39-41]. Furthermore, after $24 \mathrm{~h}$ fewer cells were growing on the electrospun zein fibers cross-linked using SHP (SHPXL) than on samples XL-L, XL-M, and XL-H cross-linked without SHP. The initial smaller number of cells attached to sample SHPXL might finally lead to the smaller number of cells growing after $24 \mathrm{~h}$. Another possible factor that might contribute to the small final cell number on sample SHPXL was the cytotoxicity of SHP, but it was not evident whether SHP had any effect on cell number at this time point $(24 \mathrm{~h})$.

To confirm the toxicity of SHP, cells were cultured for up to $120 \mathrm{~h}$ on samples SHPXL and XL-H. As seen from Figure 5 , the cell numbers on sample XL-H at all time points were higher than those on sample SHPXL. After 24 and $72 \mathrm{~h}$ cell culture the normalized cell growth values were higher on sample SHPXL (Figure 5 and $40.07 \%$ and $35.42 \%$ ) than the values on sample XL-H (Figure 5 and $39.77 \%$ and 19.24\%). Initially, cells attached to sample SHPXL might be in the optimal density range and have a higher proliferation rate. However, after $120 \mathrm{~h}$ culture sample XL-H could still maintain a relatively high normalized cell growth value (Figure 5 and 26.68\%), while the value on sample SHPXL decreased to $-5.82 \%$, indicating reduced cell growth. This phenomenon could mainly be attributed to cytotoxicity of the catalyst SHP. The cytotoxicity of SHP appeared after $120 \mathrm{~h}$ because SHP accumulated as the fibers were degraded and after a certain threshold concentration SHP was toxic to cells.

\subsection{Cell spreading and development of the cytoskeleton}

Figure 6 illustrates cell spreading and development of the cytoskeleton on the zein films and electrospun fibers. In Figure 6, the zein films and fibers exhibit a bright green fluorescent signal without labeling by any external fluorescent dyes, because zein is autoflourescent. The red areas in Figure 6 (indicated by white arrows) indicate the cytoskeleton (F-actin) in cells which have been labeled using the fluorescent dye Phalloidin 633 . After $24 \mathrm{~h}$ only a few cells had adhered to the uncross-linked zein films, with poor spreading (ZFUL), whereas 
better cell spreading was observed on the crosslinked zein films (ZFXL). Similarly, the cells on the cross-linked electrospun samples (SHPXL, XL-H) displayed much better spreading and cytoskeleton development than those on the uncrosslinked fibers (UXL). The enhanced stiffness of cross-linked zein scaffolds could probably stimulate growth of the cytoskeleton, as mentioned in the research of Lo et al. [42].

It was also shown that after cell culture for $24 \mathrm{~h}$ electrospun zein fibers, whether cross-linked or not, provided better support for cell spreading and cytoskeleton development. The advantages of an electrospun structure promoted cell growth and, hence, better cell spreading and cytoskeleton development.

\section{Conclusions}

In this paper we report a new method of developing water-stable and biocompatible electrospun zein fibers by crosslinking with citric acid. The cross-linked electrospun zein fibers showed improved morphological stability and were able to maintain their fibrous structure even after immersion at 37 ${ }^{\circ} \mathrm{C}$ in PBS for up to 15 days. In addition, the method of crosslinking electrospun zein fibers developed in this research provided better attachment, spreading and proliferation of $\mathrm{NIH}$ 3T3 fibroblast cells compared with the uncross-linked electrospun zein mats and electrospun zein fibers cross-linked with citric acid and SHP and electrospun PLA scaffolds. This study also revealed that electrospun scaffolds could provide better support for the growth of fibroblast cells compared with films as scaffolds. The improved water stability and ability of crosslinked electrospun zein fibers to support the attachment and growth of cells suggests that the cross-linking method developed has the potential to provide electrospun protein materials with those properties desired for tissue engineering and other medical applications, such as bone, cartilage and vascular grafts, subcutaneous implants, drug release systems and wound dressing.

\section{Acknowledgments}

This research work was financially supported by the Agricultural Research Division at the University of NebraskaLincoln, USDA Hatch Act and Multistate Research Project S-1026. The authors also thank the subcommittee of the Agricultural Research Division Advisory Committee of University of Nebraska-Lincoln and the Director of IAPC for the award of a John and Louise Skala Fellowship to Q.J. The authors acknowledge the kind help of Prof. Blair D. Siegfried.

\section{References}

[1] Zeugolis D, Paul R, Attenburrow G. Post-self-assembly experimentation on extruded collagen fibres for tissue engineering applications. Acta Biomater 2008; 4:1646.

[2] Chong EJ, Phan TT, Lim IJ. Evaluation of electrospun PCL/gelatin nanofibrous scaffold for wound healing and layered dermal reconstitution. Acta Biomater 2007; 3:321.

[3] Ratner BD, Hoffman AS, Schoen FJ, Lemons JE. Biomaterials science. An introduction to materials in medicine. San Diego. CA: Elsevier Academic Press; 2004.

[4] Jain D, Banerjee R. Comparison of ciprofloxacin hydrochlorideloaded protein, lipid, and chitosan nanoparticles for drug delivery. J. Biomed. Mater. Res. Part B 2008; 86B:105.

[5] MaHam A, Tang ZW, Wu H, Wang J, Lin YH. Protein-based nanomedicine platforms for drug delivery. Small 2009; 5:1706.
[6] Lee J, Cuddihy MJ, Kotov NA. Three-dimensional cell culture matrices: State of the art. Tissue Eng. B 2008; 14:61.

[7] Matthews JA, Wnek GE, Simpson DG, Bowlin GL. Electrospinning of collagen nanofibers. Biomacromolecules 2002; 3:232.

[8] Sill TJ, Recum HAv. Electrospinning: Applications in drug delivery, tissue engineering. Biomaterials 2008; 29:1989.

[9] Li WC, Cooper JA, Mauck RL. Fabrication and characterization of six electrospun poly(alpha-hydroxy ester)-based fibrous scaffolds for tissue engineering applications. Acta Biomater 2006; 2:377.

[10] Sisson K, Zhang C, Farach-Carson MC, Chase DB, Rabolt JF. Evaluation of cross-linking methods for electrospun gelatin on cell growth and viability. Biomacromolecules 2009; 10:1675.

[11] Selling GW, Woods KK, Sessa D, Biswas A. Electrospun zein fibers using glutaraldehyde as the crosslinking reagent: Effect of time and temperature. Macromol Chem Phys 2008; 209:1003.

[12] Yao C, Li XS, SongTY. Electrospinning and crosslinking of zein nanofiber mats.J Appl Polym Sci 2007; 103:380.

[13] Jiang HL, Zhao PC, Zhu KJ. Fabrication and characterization of zein-based nanofibrous scaffolds by an electro spinning method. Macromol Biosci 2007; 7:517.

[14] Fernandez A, Torres-Giner S, Lagaron JM. Novel route to stabilization of bioactive antioxidants by encapsulation in electrospun fibers of zein prolamine. Food Hydrocolloids 2009; 23:1427.

[15] Woerdeman DL, Ye P, Shenoy S, Parnas RS, Wnek GE, Trofimova O. Electrospun fibers from wheat protein: Investigation of the interplay between molecular structure and the fluid dynamics of the electrospinning process. Biomacromolecules 2005; 6:707.

[16] Barnes CP, Pemble CW, Brand DD, Simpson DG, Bowlin GL. Cross-linking electrospun type II collagen tissue engineering scaffolds with carbodiimide in ethanol. Tissue Eng 2007; 13:1593.

[17] Zhang XH, Baughman CB, Kaplan DL. In vitro evaluation of electrospun silk fibroin scaffolds for vascular cell growth. Biomaterials 2008; 29:2217.

[18] McManus MC, Boland ED, Koo HP, Barnes CP, Pawlowski KJ, Wnek GE. Mechanical properties of electrospun fibrinogen structures. Acta Biomater 2006; 2:19.

[19] Huang L, Nagapudi K, Apkarian RP, Chaikof EL. Engineered collagen-PEO nanofibers and fabrics. J Biomater Sci Polym Ed 2001; 12:979.

[20] Barnes CP, Sell SA, Boland ED, Simpson DG, Bowlin GL. Nanofiber technology: Designing the next generation of tissue engineering scaffolds. Adv Drug Deliv Rev 2007; 59:1413.

[21] Du J, Suzuki H, Nagase F, Akhand M, Ma XY, Yokoyama $\mathrm{T}$, et al. Superoxide-mediated early oxidation and activation of ASKI are important for initiating methylglyoxal-induced apoptosis process. Free Radic Biol Med 2001; 31:469.

[22] Saito Y, Nishio K, Yoshida Y, Niki E. Cytotoxic effect of formaldehyde with free radicals via increment of cellular reactive oxygen species. Toxicology 2005; 210:235.

[23] Ho Y-C, Huang F-M, Chang Y-C. Cytotoxicity of formaldehyde on human osteoblastic cells is related to intracellular glutathione levels. J Biomed Mater Res Part B Appl Biomater 2007; 83B:340.

[24] Booth K, Cummings B, Karoly WJ, Mullins S, Robert WP, Spence M, et al. Measurements of airborne methylene diphenyl diisocyanate (MDI) concentration in the US workplace. J Occup Environ Hyg 2009; 6:228.

[25] Luyn MJAv, Wachem PBv, Damink LHHO, Dijkstra PJ, Feijen J, Nieuwenhuis P. Secondary cytotoxicity of crosslink-linked dermal sheep collagens during repeated exposure to human fibroblasts. Biomaterials 1992; 13:1017. 
[26] Reuzel PGJ, Kuper CF, Feron VJ, Appelman LM, Loser E. Acute, subacute, and subchronic inhalation toxicity studies of respirable polymeric methylene diphenyl diisocyanate (polymeric Mdi) aerosol in rats. Fundam Appl Toxicol 1994; 22:186.

[27] Jayakrishnan A, Jameela SR. Glutaraldehyde as a fixative in bioprostheses and drug delivery matrices. Biomaterials 1996; 17:471.

[28] Schmidt CE, Baier JM. Acellular vascular tissues: Natural biomaterials for tissue repair and tissue engineering. Biomaterials 2000; 21:2215.

[29] Simmons DM, Kearney JN. Evaluation of collagen cross-linking techniques for the stabilization of tissue matrices. Biotechnol Appl Biochem 1993; 17:23.

[30] Reddy N, Li Y, Yang Y. Alkali-catalyzed low temperature wet crosslinking of plant proteins using carboxylic acids. Biotechnol Progr 2009; 25:139.

[31] Yang YQ, Wang LM, Li SQ. Formaldehyde-free zein fiber Preparation and investigation. J Appl Polym Sci 1996; 59:433.

[32] Xu WJ, Karst D, Yang W, Yang YQ. Novel zein-based electrospun fibers with the water stability and strength necessary for various applications. Polym Int 2008; 57:1110.

[33] Yang Y, Li S. Silk fabric nonformaldehyde crease-resistant finishing using citric-acid. J Text Inst 1993; 84:638.

[34] Reddy N, Li Y, Yang YQ. Wet cross-linking gliadin fibers with citric acid and a quantitative relationship between cross-linking conditions and mechanical properties. J Agric Food Chem 2009; 57:90.
[35] Blitterswijk CV. Tissue engineering. Burlington. MA: Academic Press; 2008.

[36] Genes NG, Rowley JA, Mooney DJ, Bonassar LJ. Effect of substrate mechanics on chondrocyte adhesion to modified alginate surfaces. Arch Biochem Biophys 2004; 422:161.

[37] Xua CY, Inaic R, Kotakib M, Ramakrishna S. Aligned biodegradable nanofibrous structure: A potential scaffold for blood vessel engineering. Biomaterials 2004; 25:877.

[38] Dong J, Sun Q, Wang J-Y. Basic study of corn protein, zein, as a biomaterial in tissue engineering: Surface morphology and biocompatibility. Biomaterials 2004; 25:4691.

[39] Rho KS, Jeong L, Lee G, Seo BM, Park YJ, Hong SD, et al. Electrospinning of collagen nanofibers: Effects on the behavior of normal human keratinocytes and early-stage wound healing. Biomaterials 2006; 27: 1452.

[40] Min BM, Lee G, Kim SH, Nam YS, Lee TS, Park WH. Electrospinning of silk fibroin nanofibers and its effect on the adhesion and spreading of normal human keratinocytes and fibroblasts in vitro. Biomaterials 2004; 25:1289.

[41] McManus M, Boland E, Sell S, Bowen W, Koo H, Simpson D, et al. Electrospun nanofibre fibrinogen for urinary tract tissue reconstruction. Biomed Mater 2007; 2:257.

[42] Lo C-M, Wang H-B, Dembo M, Wang Y-L. Cell movement is guided by the rigidity of the substrate. Biophys J 2000; 79:144. 